Article

\title{
Design Optimization of a Small-Scale Polygeneration Energy System in Different Climate Zones in Iran
}

\author{
Sara Ghaem Sigarchian *, Anders Malmquist ${ }^{(1)}$ and Viktoria Martin \\ Department of Energy Technology, KTH Royal Institute of Technology, 10044 Stockholm, Sweden; \\ anders.malmquist@energy.kth.se (A.M.); viktoria.martin@energy.kth.se (V.M.) \\ * Correspondence: sarags@kth.se; Tel.: +46-8-790-7476
}

Received: 21 February 2018; Accepted: 16 April 2018; Published: 2 May 2018

check for updates

\begin{abstract}
Design and performance of polygeneration energy systems are highly influenced by several variables, including the climate zone, which can affect the load profile as well as the availability of renewable energy sources. To investigate the effects, in this study, the design of a polygeneration system for identical residential buildings that are located in three different climate zones in Iran has been investigated. To perform the study, a model has previously developed by the author is used. The performance of the polygeneration system in terms of energy, economy and environment were compared to each other. The results show significant energetic and environmental benefits of the implementation of polygeneration systems in Iran, especially in the building that is located in a hot climate, with a high cooling demand and a low heating demand. Optimal polygeneration system for an identical building has achieved a $27 \%$ carbon dioxide emission reduction in the cold climate, while this value is around $41 \%$ in the hot climate. However, when considering the price of electricity and gas in the current energy market in Iran, none of the systems are feasible and financial support mechanisms or other incentives are required to promote the application of decentralized polygeneration energy systems.
\end{abstract}

Keywords: polygeneration system; climate zone; optimization; combined cooling, heating, and power generation (CCHP); renewable energy; particle swarm optimization (PSO) algorithm; Iran

\section{Introduction}

The share of total delivered energy in the building sector is around $20 \%$ and the share of total primary energy consumption is around $31 \%$ worldwide, which is predicted to increase by an average value of $1.5 \%$ annually from 2012 to 2040 [1,2]. Hence, due to the relatively high share of energy utilization in this sector, there is a big potential for fossil fuel consumption reduction. This, accordingly, can mitigate the negative environmental and societal impacts of fossil fuel consumption.

One of the alternative solutions to achieve higher efficiency, lower fuel consumption, and a higher share of renewable energy is the concept of decentralized combined cooling, heating, and power generation (CCHP), which is also called polygeneration. Providing power and useful heat in such systems is considered as an alternative or supplementary solution for ever-growing energy-related problems [3,4]. In addition, in a polygeneration system, multiple energy sources, including renewable and non-renewable, are used to deliver multiple energy services simultaneously, resulting in lower emissions [5].

Polygeneration system consists of several numbers of units such as combined heat and power (CHP), boilers, photovoltaic (PV) units, solar heating units, and thermal and electric storage devices. Due to the relatively large number of endogenous and exogenous variables, such as size and type of components, operating strategy, load profile, climate zones, and the availability and price of energy, the design of such systems is complicated [6-8]. Using an optimization technique for the correct sizing 
and defining the correct operating strategies can increase the performance of the system. Therefore, to define the optimal solution, development of the suitable mathematical model is necessary, and hence, modeling and optimization of small-scale polygeneration systems are carried out in several studies.

The important aspects in identifying the optimal design of such systems were the focus of various comprehensive studies [9,10]. These aspects include the technologies [11], performance assessment method, polygeneration supporting mechanisms, energy policies, operating strategies [12], decision-making variables, optimization techniques, optimization in urban application [13], and the modeling approach [4]. These surveys emphasize the necessity of further investigations on multi-criteria assessment and the feasibility study of optimization of complex polygeneration systems, including innovative storage and generation devices and the utilization of multiple fuel sources, including renewable energy [12].

A polygeneration system for a tourist center in Spain was optimized by Rubio-Maya et al. [14]. Implementation of the optimal design to supply the energy demand of the building achieved economic and environmental benefits when compared to conventional separate heat and power generation. In the presented case study, a fossil fuel consumption reduction of $18 \%$ was reported [14].

Di Somma et al. used an exergy analysis to identify the optimal design of a polygeneration energy system [15]. When compared to a conventional separate heat and power generation, 21-36\% reduction in primary exergy input for the proposed cases was achieved.

In a study performed by Sanaye et al., a small polygeneration system in a residential building that was located in the south of Iran was investigated [16]. The results showed energetic and environmental benefits of the polygeneration system. Moreover, for the presented case, due to the high availability of excess heat from the combined heat and power (CHP) units, the thermal chiller that was using this heat for cooling purposes showed advantages over the electric chiller.

Tichi et al. investigated the influences of energy policy on the performance operation of optimal polygeneration systems in Iran [17]. The price of electricity and the energy market policy in Iran were mentioned as two obstacles for the promotion of such systems. Moreover, it was mentioned that the benefits achieved are highly dependent on the optimal design and operating conditions of the system.

A CCHP system for fulfilling the load demand of an office and a commercial building in Tehran was investigated by Hanafizadeh et al. [18]. The capacity of the prime movers was optimized regarding economy for three different scenarios and the emission reduction was evaluated for the optimal designs. The optimal solutions resulted in a reduction of electricity purchase from the grid, fuel consumption, and pollutants.

The literature background shows that, despite several studies in this field, more investigations are required in order to overcome current shortcomings. As an example, in several studies, the impacts of outdoor temperature and/or part-load operation on the efficiency and power output of CHP units are not taken into account. Moreover, more research on complex polygeneration systems that consist of several generation and storage units using both renewable and non-renewable energy sources is required. Furthermore, multi-criteria optimization considering the energetic, environmental, and economic performance of a polygeneration system is an area that requires more investigation. Therefore, a method for performance evaluation and the design optimization of complex polygeneration that overcomes some of the shortcomings was proposed by the author $[13,19]$. In the developed model, a particle swarm optimization (PSO) [20,21] algorithm was used as the optimization technique. The objective function of the optimization process was to maximize the energetic, economic, and environmental performance of the system relative to a defined reference system.

The model aims to optimize a semi self-sustaining polygeneration system, which minimizes the fossil fuel consumption and maximizes the use of renewable energy. Therefore, in the operating strategies, the priority was given to renewable heat and power. Several generation (heating, cooling and electricity) and storage units (heat, cold and electric) that were driven by renewable and non-renewable energy sources were considered in the model. In similar studies, one or more components, which are of interest, are missing, and that has a significant impact on the performance of the polygeneration 
system. The grid is only used for balancing purposes and increasing the excess power for merely maximizing the profit by playing a role in the day-ahead market is not included in the operating strategies. The details of the optimization tool, energy flow model, and embedded operating strategies are available in the original paper [13]. In the present study, however, a general outline of the model, the main principle of the optimization model, and the performance evaluation method are described briefly.

The climate zone is one of the parameters that significantly influences the load profile, ambient temperature, availability of the renewable energy sources, such as solar radiation and wind speed, and the operational characteristics of the prime movers [22]. This consequently can affect the design and performance of polygeneration systems. Hajabdollahi et al. investigated the performance of a polygeneration system to provide the energy demand of hotel building in hot, moderate, and cold climate in Iran [23]. The objective function was to maximize the annual economic benefits as compared to conventional separate heat and power production system. The size of each component and the operating strategies were optimized. The highest annual benefit was achieved in the hot and moderate climate, and the lowest was achieved in the cold climate. Li et al. proposed an improved method for determining the energy saving ratio of polygeneration systems in various climates using standard regulation in term of energy management through [24]. The influence of weather on the size of prime movers [25] and the effect of temperature on the CCHP systems were investigated by Ebrahimi et al. [26]. The operation of CCHP systems was optimized in terms of energy, economy, and carbon dioxide emission reduction by Cho et al. for different locations with different climate conditions [27].

When considering the literature, it can be concluded that climate zone is one of the important parameters that can affect the benefits that are achieved by a CCHP system. Hence, to make a correct conclusion about the benefits achieved from a polygeneration system, the effects on the performance should be determined and realized [24]. However, despite the existing studies, many of the investigated CCHP systems did not include solar heating and power components and storage devices. In addition, due the number of studies are limited and more investigation on the impacts of climate zones on the performance and design of complex polygeneration systems, including solar heating units, solar power installations, and storage devices is required.

Therefore, in this study, in order to examine these effects, the optimal design and performance of complex polygeneration systems for an identical residential building complex that is located in three different climate zones in Iran are investigated. Iran is chosen due to its climate span, but with approximately the same price for electricity and natural gas in the different locations. Moreover, Iran is an attractive case due to the extensive use of fossil fuels for heat and power production presently while it has an abundance solar energy, which can be used in the future energy system.

\section{Problem Statement}

In this section, the characteristics of the proposed method, system configuration, and problem formulation are described briefly. Details of the method, operating strategies, and performance evaluation technique can be found in the method paper [13].

A common approach for the assessment of a polygeneration energy system is to evaluate its performance relative to a reference system as used in previous studies [28-33]. In the section below, the reference system and polygeneration system that were used in this study are illustrated and described in detail.

\subsection{Reference System}

The schematic of the reference system is illustrated in Figure 1. In the reference system, the heating is provided by a natural gas driven boiler and the electricity is imported from the utility grid, which is a conventional fossil fuel driven power plant. The cooling demand is provided by an electric chiller. 


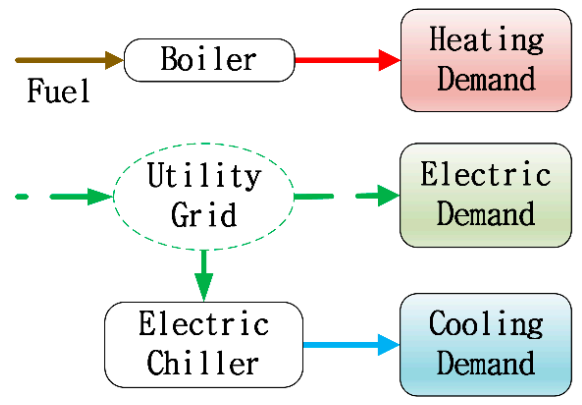

Figure 1. Block diagram of the reference system $[13,19]$.

The total power demand is the summation of the building's power demand and the electricity demand of the electric chiller. The equivalent energy of the fuel consumption by the utility grid is calculated by the equations below:

$$
\begin{gathered}
F_{\text {grid }}^{\text {Ref }}=\frac{P_{\text {grid }}^{\text {Ref }} \times \Delta t}{\eta_{\text {el }}^{\text {Grid }} \times \eta_{\mathrm{dl}}^{\text {Grid }}} \\
P_{\text {grid }}^{\text {Ref }}=P_{\text {dem_dir }}+P_{\text {Ech }}^{\text {Ref }}
\end{gathered}
$$

where

- $\quad P_{\text {grid }}^{\text {Ref }}$ is the supplied power by the grid, $P_{\text {dem_dir }}$ is the internal electricity demand and $P_{\mathrm{Ech}}^{\text {Ref }}$ is the electric chiller power demand, and

- $\eta_{\mathrm{el}}^{\text {grid }}$ is the power plant efficiency, $\eta_{\mathrm{dl}}^{\text {Grid }}$ is the grid distribution line efficiency which consider the losses through the distribution and transmission lines and $\Delta \mathrm{t}$ is the time-step.

The total corresponding energy of the fuel consumption $\left(F_{\text {tot }}^{R e f}\right)$ in the reference system is given as below:

$$
F_{\mathrm{tot}}^{\mathrm{Ref}}=F_{\text {grid }}^{\mathrm{Ref}}+F_{\mathrm{boiler}}^{\mathrm{Ref}}
$$

where $F_{\text {boiler }}^{\text {Ref }}$ and $F_{\text {grid }}^{\text {Ref }}$ are the corresponding energy of the fuel utilization in the boiler and the utility grid respectively.

\subsection{Polygeneration System Configuration}

The polygeneration system comprises of power, heating, and cooling units that are accompanied by thermal and electric storage devices. A block diagram of the system is illustrated in Figure 2 . The power is provided by solar panels, wind turbines, and a combined heat and power (CHP) unit. The heat can be supplied by the heat recovery unit (HRU) annexed to the CHP, an auxiliary boiler and solar heating (SHU) units. Cooling is supplied by a thermal chiller (Tch) and/or an electric chiller. To exploit the excess heat and power and to overcome the fluctuating nature of renewable sources, thermal and electric storages are added in the configuration. In the default model, the system is connected to the grid; however, it can be easily modified for an off-grid application.

The total equivalent energy of the fuel consumption $\left(F_{\text {tot }}^{\text {Poly }}\right)$ is the accumulated fuel energy that is utilized in the boiler ( $F_{\text {boiler }}^{\text {Poly }}$ ), the equivalent energy of the fuel consumption of the imported power from the grid $\left(F_{\text {grid }}^{\text {Poly }}\right)$, and the equivalent energy of the fuel consumption in the CHP unit ( $\left.F_{\text {chp }}^{\text {Poly }}\right)$, which can be calculated by the equation below:

$$
F_{\text {tot }}^{\text {Poly }}=F_{\text {boiler }}^{\text {Poly }}+F_{\text {grid }}^{\text {Poly }}+F_{\text {chp }}^{\text {Poly }}
$$


The corresponding energy of the fuel consumption of the grid import $\left(P_{\mathrm{g}, \mathrm{imp}}^{\text {Poly }}\right)$ can be estimated by the following equation:

$$
F_{\text {grid }}^{\text {Poly }}=\frac{\left(P_{\text {g,imp }}^{\text {Poly }}\right) \times \Delta t}{\eta_{\mathrm{el}}^{\text {grid }} \times \eta_{\mathrm{dl}}^{\text {grid }}}
$$

where $\eta_{\mathrm{el}}^{\text {grid }}$ is the efficiency of the power plant, $\eta_{\mathrm{dl}}^{\text {grid }}$ is the grid efficiency that considers the losses in the distribution and transmission losses and $\Delta \mathrm{t}$ is the time-step of the simulation.

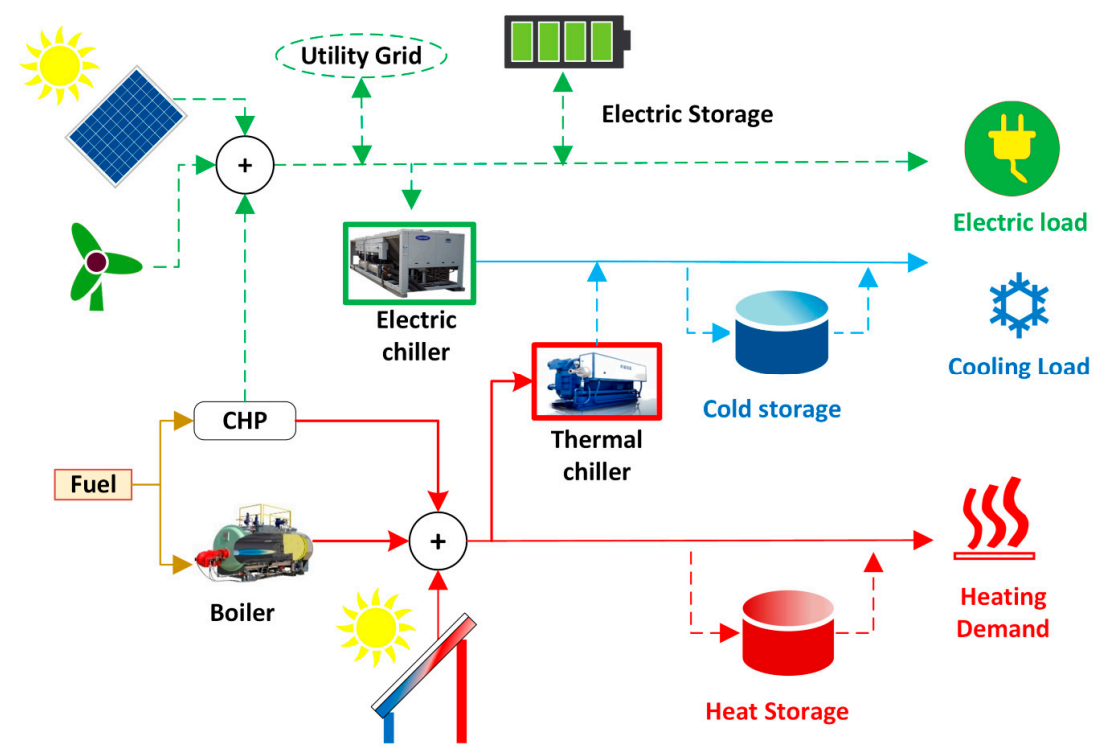

Figure 2. Block diagram of the polygeneration system [13,19].

It should be mentioned that, since a high degree of self-sustainability in term of power is the main intention of the optimization model, generating excess power on purpose and participating in the day-ahead market is out of the scope of this work. In other words, maximizing profit by selling the electricity to the grid is not an immediate goal in the optimization process.

\section{Operating Strategy Description}

There are three operating strategies incorporated in the model namely, following electric load (FEL), modified base load (MBL), and following thermal load (FTL). In the FEL strategy, the CHP provides the electricity demand, which follows the electric demand at each time-step, resulting in low excess power from the CHP. In the MBL, the CHP is operated at its rating power and provides a base load as far as the demand is above the base load. However, if the demand falls below the base load, the CHP follows the power demand and operates similarly to the FEL. In the FTL strategy, the CHP units supply the total heating demand and the boiler operates for covering more heating demand. In this case study, being self-sustained in terms of power is assumed to be an important issue, and therefore, the FEL is chosen as the operating strategy.

The electricity demand is firstly provided by solar or wind energy, and then through discharging the storages and next by the CHP units. If there is any excess or deficit power, it will be exported or imported to/from the grid. The boiler will be operated if there is any heat deficit. In the case of excess heat, it will be stored in the storage. Additional features of the operating strategies can be acquired from the method paper [13]. 


\subsection{Performance Evaluation}

To investigate the benefits of polygeneration systems, their performance relative to the reference system regarding energy, economy, and environment should be evaluated. Annualized Total Cost Saving Ratio (ATCSR), Fuel Saving Ratio (FSR), and $\mathrm{CO}_{2}$ Emission Reduction Ratio (CO2ERR) are the three criteria that are used for energetic, economic, and environmental evaluation (3-E analysis) of the polygeneration system as frequently used in the similar analysis [28-33]. In this section, the performance evaluation method is explained in brief and more details are available in the original work [13].

The $\mathrm{CO}_{2}$ Emission Reduction Ratio (CO2ERR) is estimated, as below:

$$
C O 2 E R R=1-\frac{\mathrm{CO}_{2 \text { tot }}^{\text {Poly }}}{\mathrm{CO}_{2 \text { tot }}^{\text {Ref }}}
$$

where $\mathrm{CO}_{2}^{\text {toty }}$ and $\mathrm{CO}_{2}^{\text {tot }}$ Ref are the $\mathrm{CO}_{2}$ emissions of the polygeneration and reference system, respectively.

Fuel Saving Ratio (FSR) is calculated by the following equation:

$$
F S R=1-\frac{F_{\text {tot }}^{\text {Poly }}}{F_{\text {tot }}^{\text {Ref }}}
$$

where $F_{\text {tot }}^{\text {Poly }}$ and $F_{\text {tot }}^{\text {Ref }}$ are the equivalent energy of the fuel utilization in the polygeneration system and reference system, respectively.

The Annualized Total Cost Saving Ratio (ATCSR) is given, as follows:

$$
A T C S R=1-\frac{A T C_{\text {tot }}^{\text {Poly }}}{A T C_{\text {tot }}^{\text {Ref }}}
$$

where $A T C_{\text {tot }}^{\text {Ref }}$ and $A T C_{\text {tot }}^{\text {Poly }}$ are the annualized total cost of the reference and the polygeneration system through its lifetime.

Payback Period (PBP) and Internal Rate of Return (IRR) are the other metrics that are used in the economic evaluation of the polygeneration system.

\section{Optimization Problem Formulation}

In this part, a general overview of the objective function and the optimization method is presented. Details of the optimization problem formulation and the operating strategies are provided in the previous work $[13,19]$.

\subsection{Optimization Model Overview}

As shown in Figure 3, the optimization tool has three main sections: the optimizer; the performance analysis; and, the energy flow model. A Particle Swarm Optimization (PSO), which is a population-based algorithm, is used as the optimization technique. The PSO was introduced by Kennedy and Eberhart [20], and it is shown to be a cost-effective method for identifying high-quality solutions [34,35]. The operating mechanism of the PSO algorithm is explained in the method paper [13], and more details about the PSO algorithm can be found in the original work by Kennedy and Eberhart [20]. 


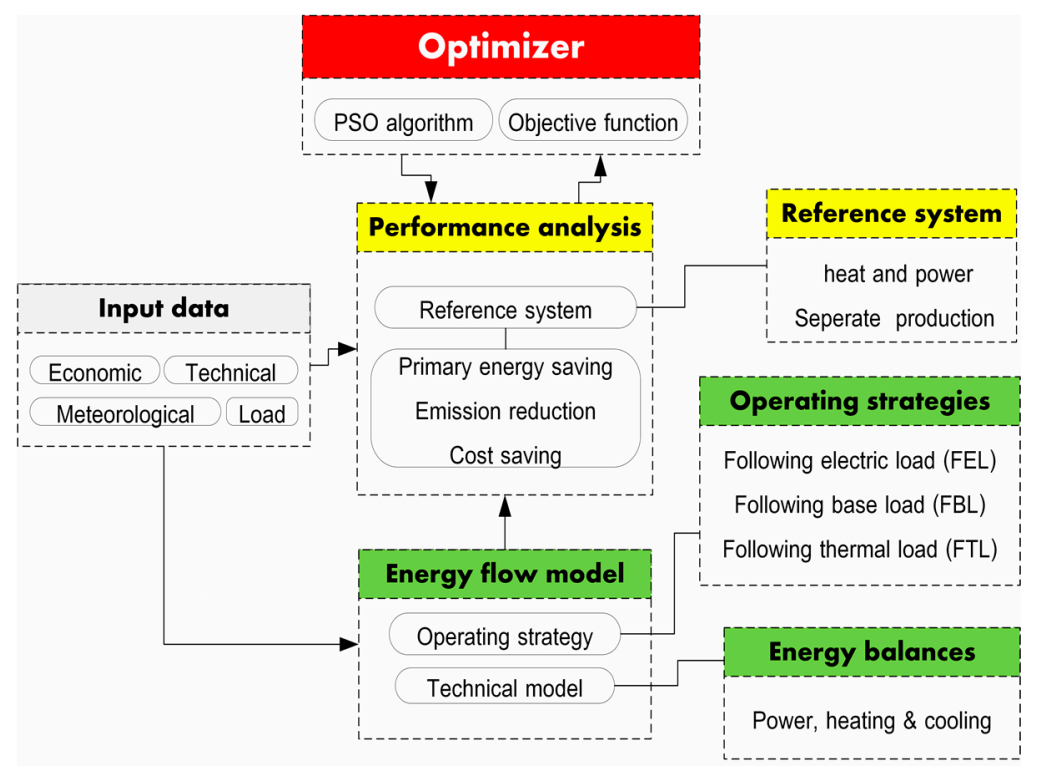

Figure 3. Flowchart of the optimization model.

\subsection{Objective Function}

The objective function is formulated in order to maximize the three metrics that are mentioned in Section 2.3: FSR; ATCSR; and, CO2ERR. The decision variables are the size of the components and the goal of the optimization process is to maximize an integrated saving ratio (ISR) that includes all of the mentioned metrics and is given as follows:

$$
I S R=w_{1} \times F S R+w_{1} \times C O 2 E R R+w_{3} \times A T C S R
$$

where $w_{1}, w_{2}$ and $w_{3}$ are the weighting factors.

The objective function is formulated as a minimization problem, as given below:

$$
\text { Objective function }=\text { Minimize }\left(\frac{1}{I S R}\right)
$$

In this study, the economic weighting factor $w_{3}$ is 0.5 and the environmental and energetic weighting factors are 0.25 due to their interdependency. However, a further optimized design can be investigated by considering other combinations of energy, economy, and environmental criteria through a minor alteration of the objective function by considering the other distribution of the weighting factors.

\section{Application to the Case Study}

To investigate the impact of climate zones on the optimal design of a polygeneration system and its performance, the energy system of an identical residential building that is located in three climate zones in Iran is optimized for each location. Since the building's specification and the determination of its load demand characteristics are beyond the scope of this study, the data from another study that was conducted by Ehyaei et al. [36] is used.

\section{Case Study Description}

The load demand of a hypothetical 10-story residential building with four apartments in each floor and each apartment with an average floor area of $200 \mathrm{~m}^{2}$ was investigated by Ehyaei et al. [36]. Ehyaei and Bahadori, determined the load demand of the identical residential building that was located in three cities with different climate specifications in Iran [37]: Ahvaz in south of Iran in 
a desert climate with very hot summer and mild, short winters; Tehran in the north of Iran in a cold semi-arid climate and moderate winters; and, Hamedan in north-west of Iran in a cold climate with very cold winters, as shown in Figure 4. The TRNSYS database is used to identify the weather data, including the solar radiation, temperature, and wind speed with an hourly time-step [38]. The average daily solar radiation in Ahvaz, Tehran and Hamedan are 5.4, 4.7 and $4.6 \mathrm{kWh} / \mathrm{m}^{2} /$ day, respectively. The ambient temperature and wind speed for each city are presented in Table 1.

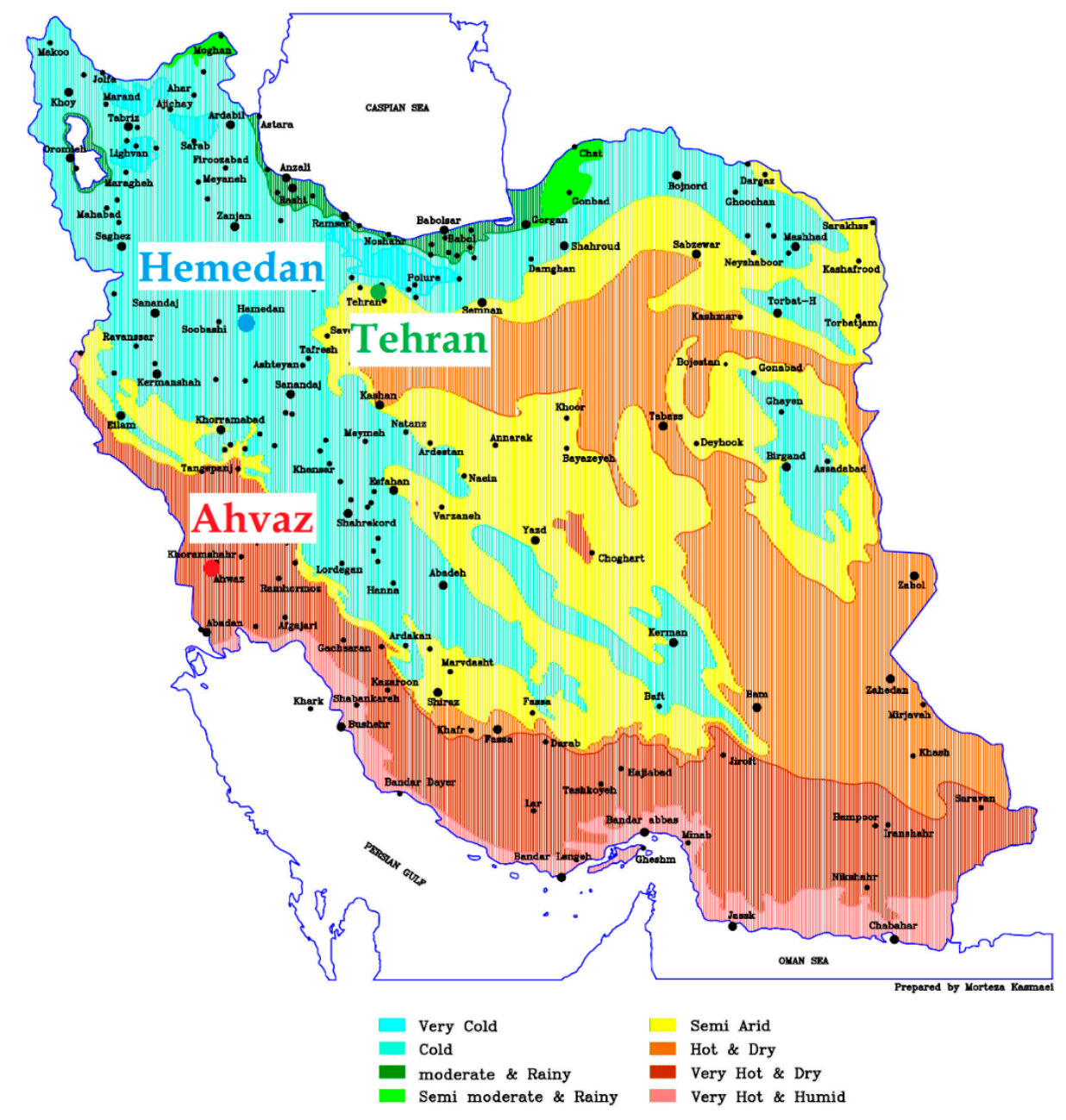

Figure 4. Climate map of Iran and the location of the selected cities [37].

Table 1. Ambient temperature and wind speed for the identified cities.

\begin{tabular}{cccc}
\hline \multirow{2}{*}{ City } & \multicolumn{2}{c}{ Ambient Temperature $\left({ }^{\circ} \mathbf{C}\right)$} & Wind Speed $(\mathbf{m} / \mathbf{s})$ \\
\cline { 2 - 4 } & Max & Min & Max \\
\hline Ahvaz & 47 & 13 & 4.6 \\
Tehran & 37 & -2 & 5 \\
Hamedan & 32 & -10 & 10 \\
\hline
\end{tabular}

A comprehensive investigation regarding the thermal and electrical demand of a residential building in Tehran, Iran was carried out by Ehyaei et al. [36]. Then, the study was performed for the same building as if it was located in Hamedan and Ahvaz. The average domestic hot water load demand is shown in Figure 5, however, the profile changes on a monthly basis. The power demand of the building excluding the power demand of the electric chiller is also shown in Figure 5. These two load profiles are assumed to be the same in all of the buildings. The heating and cooling load profiles 
of the building for the representative months in each city are shown in Figure 6. More information about the building specifications and its load demand can be found in the original work [36].

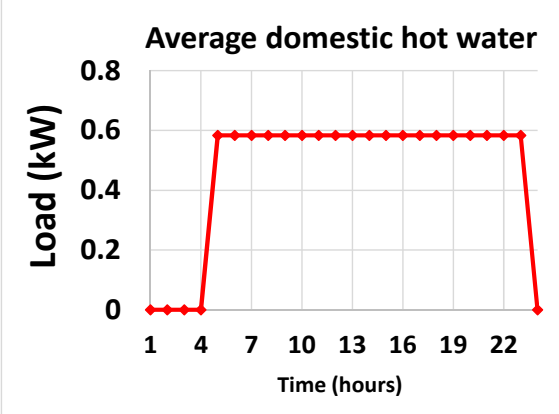

(a)

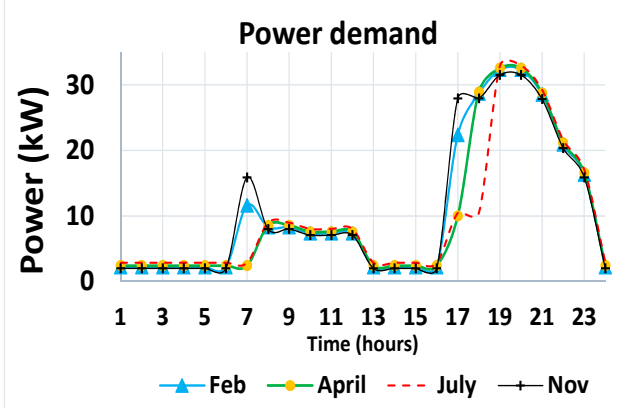

(b)

Figure 5. Average domestic hot water load demand (a) and electric power demand of the buildings for four months (b).
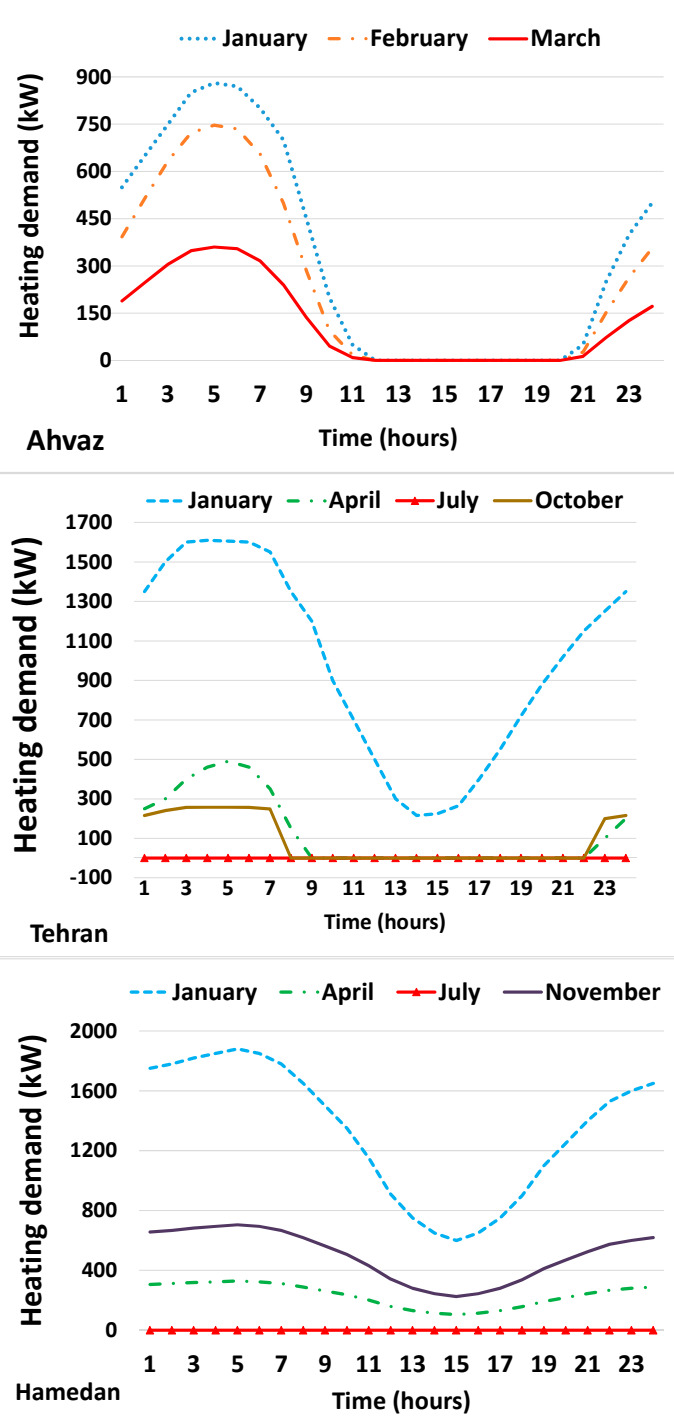

(a)
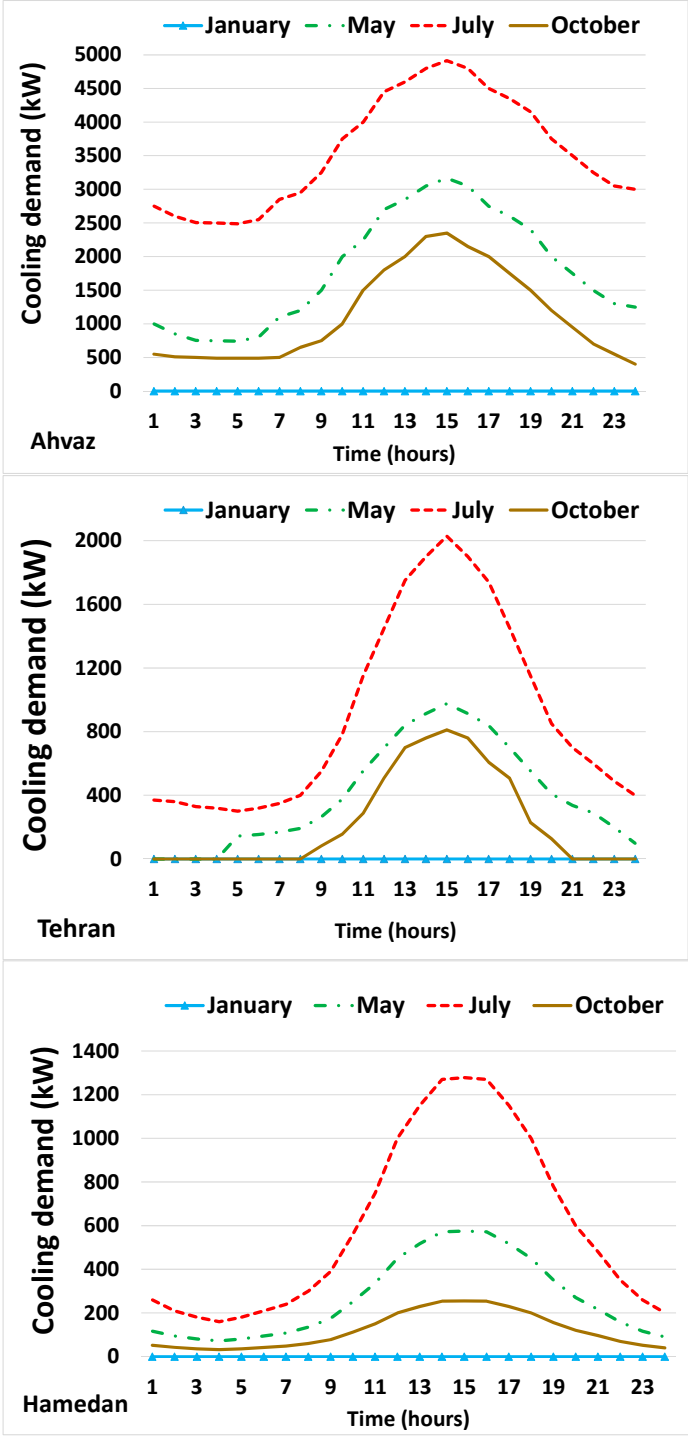

(b)

Figure 6. Heating (a) and cooling (b) demand of the building in Ahvaz, Tehran, and Hamedan [36]. 
In the present study, the model was simulated for one-year operation running with an hourly time-step $(8760 \mathrm{~h})$. The peak power, heating, and cooling demand of the building and the aggregated electricity, heating, and cooling demand during a one-year operation are shown in Table 2. For the economic evaluation, the interest rate and inflation rate of $13 \%$ and $10 \%$ are assumed, respectively, and the lifetime of the project is considered to be 20 years. The efficiency of the power plant (gas turbine based) and the efficiency of the grid in the reference system are assumed to be $35 \%$ and $88 \%$, respectively, corresponding to the low efficiency of the power plants as well as the grid transmission lines in Iran $[39,40]$.

Table 2. Peak demand and annual aggregated power, heating, and cooling demand of the building [36].

\begin{tabular}{ccccc}
\hline \multirow{2}{*}{ Demand } & Type & \multicolumn{3}{c}{ City } \\
\cline { 3 - 5 } & & Ahvaz & Hamedan & Tehran \\
\hline \multirow{3}{*}{ Peak demand $(\mathrm{kW})$} & Electricity & 33 & 33 & 33 \\
& Heating & 881 & 1881 & 1590 \\
& Cooling & 4915 & 1278 & 2028 \\
\hline \multirow{3}{*}{ Annual demand $(\mathrm{MWh})$} & Heating & 296.02 & 3729.6 & 3023.9 \\
& Cooling & 11,347 & 1807.7 & 2528.2 \\
& Electricity & 88.2 & 88.2 & 88.2 \\
\hline
\end{tabular}

All of the operating strategies that are embedded in the system have advantages and drawbacks, and the choice of operating strategy is related to the project requirement and specification [19]. However, since self-sustainability in terms of power and independency from the grid is assumed to be necessary in the defined case, the FEL operating strategy is assigned.

Technical specification of the components, the related costs, the electricity and gas tariff, and the grid emission factors that are used in the case study are shown in Tables 3-6. Due to the limited available space for solar PV and solar heating panels and thermal storages, the sizes of these components are limited in the search space, as shown in Table 7.

Table 3. Technical specification of each component.

\begin{tabular}{ccc}
\hline Component & Parameter & Value \\
\hline \multirow{2}{*}{ Solar PV System } & Module efficiency (\%) & 16 \\
& Inverter efficiency $(\%)$ & 98 \\
\hline \multirow{2}{*}{ Wind Turbine } & Nominal power of one turbine $\left(\mathrm{kW}_{\mathrm{el}}\right)$ & 20 \\
& Cut-in/out/rated speed (m/s) [41] & $4 / 16 / 11$ \\
\hline CHP & Efficiency (\%) [42-44] & $26-34$ \\
& Heat recovery unit thermal efficiency (\%) & 85 \\
\hline Auxiliary Boiler & Heat loss in the CHP unit $(\%)$ & 3 \\
\hline \multirow{2}{*}{ Battery Storage } & Thermal efficiency (\%) & 80 \\
\hline Thermal Chiller [45] & Round trip Efficiency (\%) & 90 \\
\hline Electric Chiller & Cinimum /maximum State of Charge (\%) & $20 / 90$ \\
\hline Solar thermal & Coefficient of performance (COP) & 0.7 \\
\hline Thermal storages & Loss coefficient of the storage at each time-step (\%) & 3 \\
\hline
\end{tabular}


Table 4. Capital cost of each component.

\begin{tabular}{ccccc}
\hline Component & Capital Cost & Unit & Maintenance Cost & Unit \\
\hline Solar PV & 2000 & $\mathrm{USD} / \mathrm{kW}_{\mathrm{el}}$ & 4 & $\mathrm{USD} / \mathrm{kW}$ year \\
Solar collector [46] & 250 & $\mathrm{USD} / \mathrm{m}^{2}$ & 0.5 & $\mathrm{USD} / \mathrm{m}^{2}$ year \\
Wind turbine & 4000 & $\mathrm{USD} / \mathrm{kW}_{\mathrm{el}}$ & 25 & $\mathrm{USD} / \mathrm{kW}$ year \\
$\mathrm{CHP}$ (Micro gas turbine) [15,47] & $1200-2450$ & $\mathrm{USD} / \mathrm{kW}_{\mathrm{el}}$ & $0.005-0.016$ & $\mathrm{USD} / \mathrm{kWh}_{\mathrm{el}}$ \\
Auxiliary boiler & 80 & $\mathrm{USD} / \mathrm{kW}_{\text {th }}$ & 0.003 & $\mathrm{USD} / \mathrm{kW}_{\mathrm{th}}$ \\
Battery storage & 350 & $\mathrm{USD} / \mathrm{kW}$ th & 0.002 & $\mathrm{USD} / \mathrm{kWh}_{\mathrm{el}}$ \\
Thermal chiller [15,48,49] & $230-700$ & $\mathrm{USD} / \mathrm{kW}_{\mathrm{c}}$ & 0.001 & $\mathrm{USD} / \mathrm{kW}_{\mathrm{c}}$ \\
Electric chiller [49,50] & $150-380$ & $\mathrm{USD} / \mathrm{kW}$ & 0.001 & $\mathrm{USD} / \mathrm{kW}_{\mathrm{c}}$ \\
Heat storage [51] & 20 & $\mathrm{USD} / \mathrm{kWh}$ & 0.002 & $\mathrm{USD} / \mathrm{kWh}$ year \\
Cold storage [52] & 30 & $\mathrm{USD} / \mathrm{kWh}$ & 0.002 & $\mathrm{USD} / \mathrm{kWh}$ year \\
\hline
\end{tabular}

Note: Estimated costs are based on the mentioned references and available online data.

Table 5. Electricity ${ }^{1}$ and natural gas price in the market [53].

\begin{tabular}{ccc}
\hline Commodity & Hours & Unit Price (USD/kWh) \\
\hline \multirow{3}{*}{ Electricity purchase } & $(22: 00-6: 00)$ & 0.04 \\
& $(7: 00-17: 00)$ & 0.05 \\
& $(18: 00-22: 00)$ & 0.06 \\
\hline Electricity sell & - & 0.05 \\
\hline Natural Gas & - & 0.009 \\
\hline
\end{tabular}

${ }^{1}$ The presented tariff is hypothetical and according to the current energy market in Iran.

Table 6. Emission factor.

\begin{tabular}{lc}
\hline \multicolumn{3}{l}{ Standard Emission Factor $\left[\mathbf{k g} \mathbf{C O}_{\mathbf{2}} \mathbf{k W h}\right]$} \\
\hline Natural gas [54] & 0.202 \\
Grid (Iran) [55] & 0.69 \\
\hline
\end{tabular}

Table 7. Optimization search space limitation.

\begin{tabular}{ccc}
\hline \multirow{2}{*}{ Component } & \multicolumn{2}{c}{ Search Space } \\
\cline { 2 - 3 } & Min & Max \\
\hline Solar collector $\left(\mathrm{m}^{2}\right)$ & 0 & 500 \\
Heat storage $(\mathrm{kWh})$ & 0 & 1000 \\
Cold storage $(\mathrm{kWh})$ & 0 & 1000 \\
Solar PV $\left(\mathrm{kW}_{\mathrm{el}}\right)$ & 0 & 230.4 \\
\hline
\end{tabular}

\section{Result and Discussion}

The optimization was performed for a polygeneration system with the FEL strategy in Ahvaz, Hamedan, and Tehran. A comparative analysis between the cities was carried out while considering the following terms:

- $\quad$ Size of components

- Performance (3-E analysis)

- Economy

\subsection{Component Size}

The optimal size of polygeneration systems for each city is shown in Figure 7. There is no battery, wind turbine, or solar heating panel in any of the optimal solutions due to their high price and the low price of electricity and gas purchase in the energy market in Iran. The size of the PV panels is the maximum value of the search space, since it decreases the $\mathrm{CO}_{2}$ emission and increases the economy of 
the system by avoided electricity and fuel purchase costs. The sizes of the electric and thermal chillers are the highest in Ahvaz and the lowest in Hamedan, owing to the high and low cooling demands in these locations, respectively. Consequently, the building in Ahvaz has the largest CHP system since the total power demand highly depends on the size of the electric chiller. In other words, the CHP system cover the power demand (FEL operating strategy) and therefore a larger capacity of CHP system in a city with a higher total power demand (Ahvaz) would be required. The same reasoning holds true in explaining the smaller CHP unit size in Hamedan.

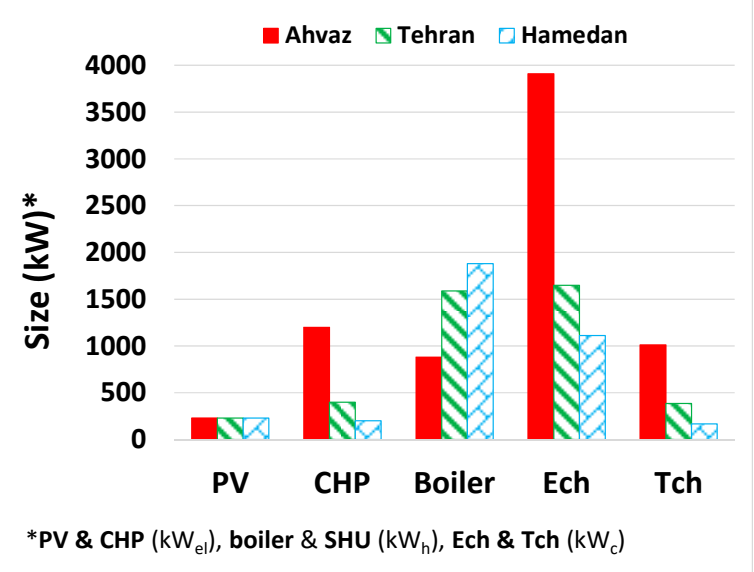

(a)

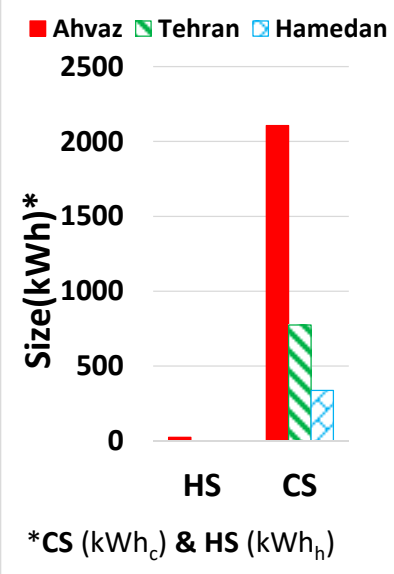

(b)

Figure 7. (a) Size of the components; photovoltaic (PV) (solar panels), CHP (combined heat and power), Ech (electric chiller) and Tch (thermal chiller); (b) HS (heat storage), CS (cold storage).

The cold storage appeared in all of the cities with the highest value in Ahvaz because of its high cooling demand. The heat from the CHP unit is used for the heating purpose or in the thermal chiller for cooling purposes. Therefore, there is no heat storage in Hamedan and Tehran, and the size of heat storage in Ahvaz is quite small.

\subsection{Performance Analysis}

Performance of the systems in terms of energy, environment and economy are shown in Figure 8. As shown, based on the integrating saving ratio (ISR), the performance of the polygeneration system is the highest in Ahvaz and the lowest in Hamedan, which are the hottest and coldest cities, respectively. Similarly, FSR, CO2ERR, and ISR are the highest in Ahvaz and the lowest in Hamedan. The CO2ERR in Ahvaz, Tehran, and Hamedan are around $41 \%, 34 \%$ and $27 \%$, respectively. This shows the significant environmental benefits of the polygeneration systems in all of the cases, especially for a city with a hot climate like Ahvaz. However, the ATCSR as an economic indicator is relatively low in all of the cases, which is an obstacle in promoting the application of polygeneration systems in Iran. More details about the economy of the system are further discussed in Section 5.3.

The total heating, cooling, and electricity production by the polygeneration system, the amount of excess heat and the amount of imported and exported electricity from/to the grid for each city are shown in Figure 9. In Ahvaz, due to the high cooling demand, the size of the CHP to provide the cooling demand of the electric chiller is large, and consequently the amount of heat that is provided by the CHP is relatively high as well. Part of this heat is used for cooling purposes through the thermal chiller. However, not all of the exhaust heat can be used, and therefore, the amount of excess heat in Ahvaz is higher than the other two cities. In Hamedan and Tehran, the amount of available heat from the CHP units is less and the heat can be exploited for heating purposes due to the colder winters. The amount of exported electricity is the highest in Hamedan and the lowest in Ahvaz. This is mainly due to the size of solar installations, which is the same for all of the cities, while the amount of total 
power demand (including the electricity demand of the electric chiller) is the lowest in Hamedan and the highest in Ahvaz. In addition, during the heating season, which is relatively long in Hamedan, the power demand is comparatively low and the electricity demand is imported from the grid instead of running the CHP at low part-load. Therefore, the amount of imported power is relatively high during the cold season in Hamedan.

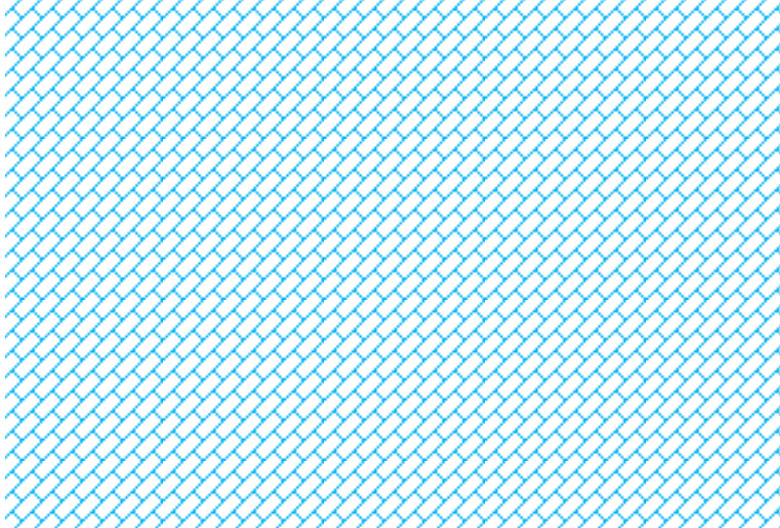

Figure 8. Fuel saving ratio (FSR), $\mathrm{CO}_{2}$ emission reduction ratio (CO2ERR), annualized total cost saving ratio (ATCSR), and integrated savings ratio (ISR) in Ahvaz, Tehran, and Hamedan.

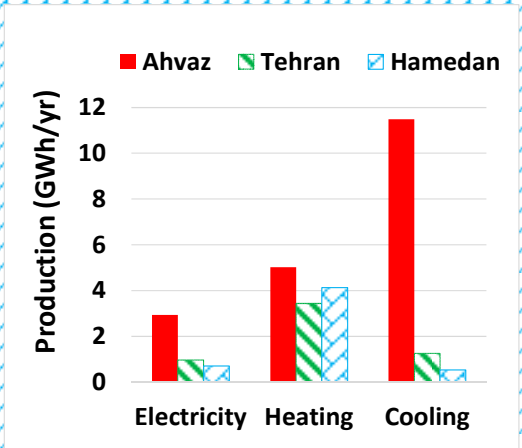

(a)

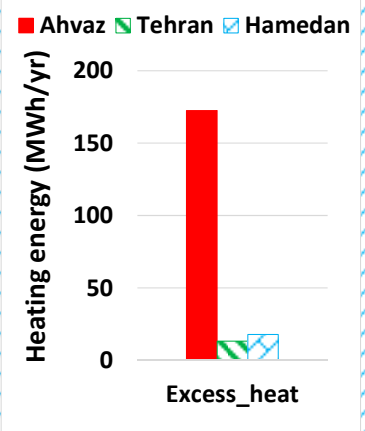

(b)

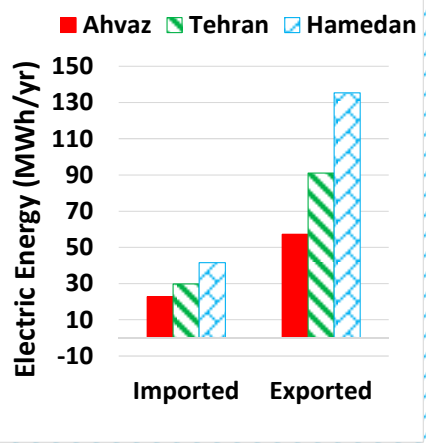

(c)

Figure 9. Yearly production (a); excess heat (b) and imported/exported power (c).

As presented in Figure 8, the value of CO2ERR for the polygeneration system that is located in Ahvaz is the highest. This value is related to the heating, cooling, and electricity production. However, as shown in Figure 10, the specific $\mathrm{CO}_{2}$ emission factor, which is the amount of $\mathrm{CO}_{2}$ emission per $\mathrm{kWh}$ produced electricity by the polygeneration system is the highest $\left(0.24 \mathrm{~kg} \mathrm{CO}_{2} / \mathrm{kWh}_{\mathrm{el}}\right)$ in Ahvaz and the lowest $\left(0.1 \mathrm{~kg} \mathrm{CO}_{2} / \mathrm{kWh}_{\mathrm{el}}\right)$ in Hamedan. This is mainly due to the high share of power production by the solar PV units in Hamedan, as shown in Figure 10. The share of power generation by the PV panels is the highest (65\%) in Hamedan and the lowest (17\%) in Ahvaz. This can be explained by the fact that while the size of solar panel installations is the same in all of the cities, the power demand is the highest in Ahvaz and the lowest in Hamedan.

The share of power self-consumption (the ratio of the consumed power in the building to the total generated power by the polygeneration system) has the highest $(98 \%)$ and lowest $(81 \%)$ values in Hamedan and Ahvaz, respectively. Consequently, the share of exported power in Hamedan is the highest, while this value is the lowest in Ahvaz. On the other hand, Ahvaz exhibits the share of power generation by polygeneration systems of $99 \%$, which in comparison to Hamedan (93\%) reveals higher self-sufficiency of the system in Ahvaz. 


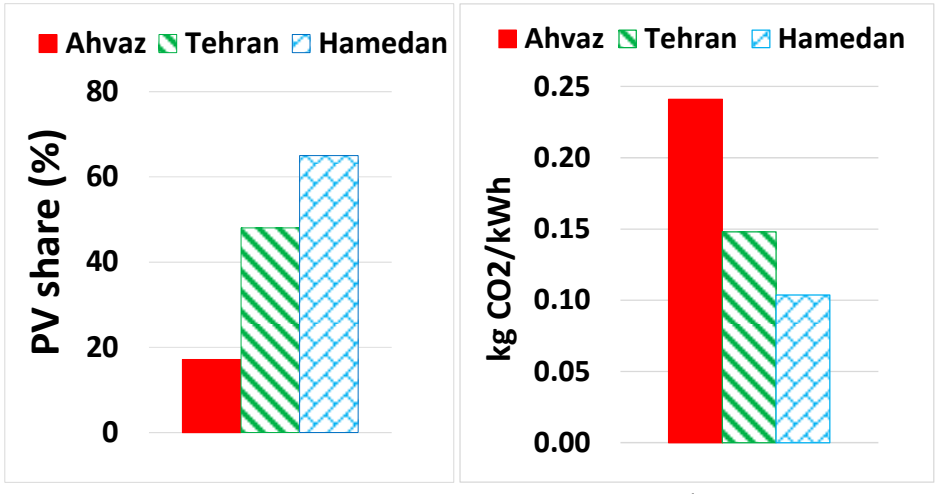

(a)

(b)

Figure 10. Share of solar PV units (a) and specific $\mathrm{CO}_{2}$ emission factor (b).

To identify the importance of the thermal chiller and cold storage in the system, the share of cooling production by the thermal chiller and the share of cold storage in cooling demand supply are shown in Figure 11. As shown, the share of cooling production by the thermal chiller is the highest in Ahvaz (26\%) due to the higher amount of exhaust heat from the CHP unit in Ahvaz. The share of cooling-demand supply by the cold storage in Ahvaz and Tehran are around 30\%, while in Hamedan it is around $24 \%$. These figures show the significant role of the thermal chiller and cold storage in increasing the performance of the polygeneration system as these devices can exploit the excess heat and power and use them for cooling purposes.

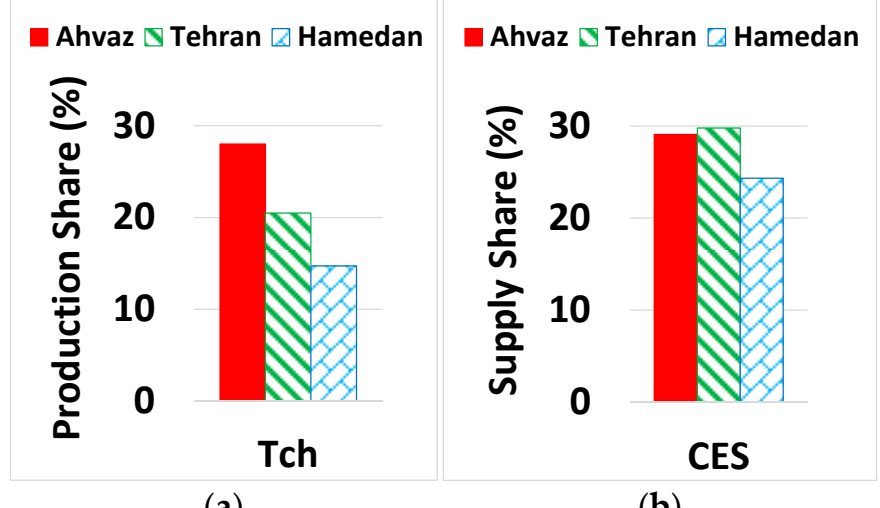

(a)

(b)

Figure 11. Share of cooling production by the thermal chiller (Tch) (a) and the share of cold storage in cooling demand supply (b).

\subsection{Economic Evaluation}

The cost breakdown and the share of each type of cost for the polygeneration systems are shown in Figure 12. The capital cost is the highest in Ahvaz and the lowest in Hamedan, which is mainly related to the size of the CHP system. The fuel cost is the highest in Ahvaz and the lowest in Tehran. The fuel consumption in Ahvaz is mainly related to the fuel consumption in the CHP system. The fuel consumption in Hamedan is mainly due to the high heating demand and high amount of imported power from the grid. The costs/benefits of electricity purchased/sold from/to the grid are proportional to the amount of imported and exported electricity. 


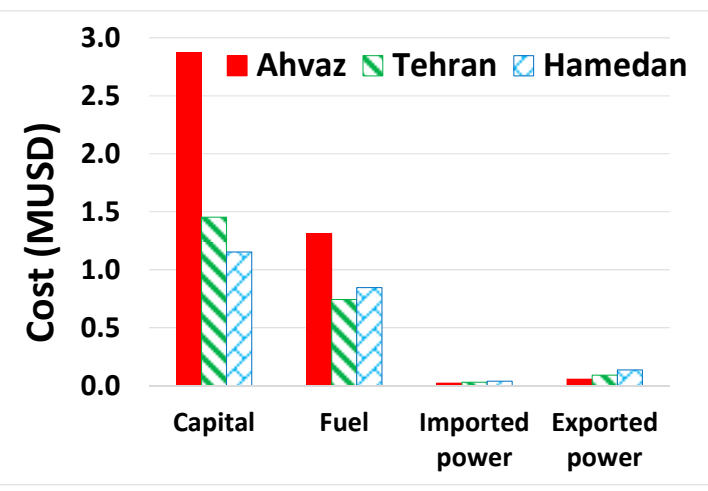

(a)

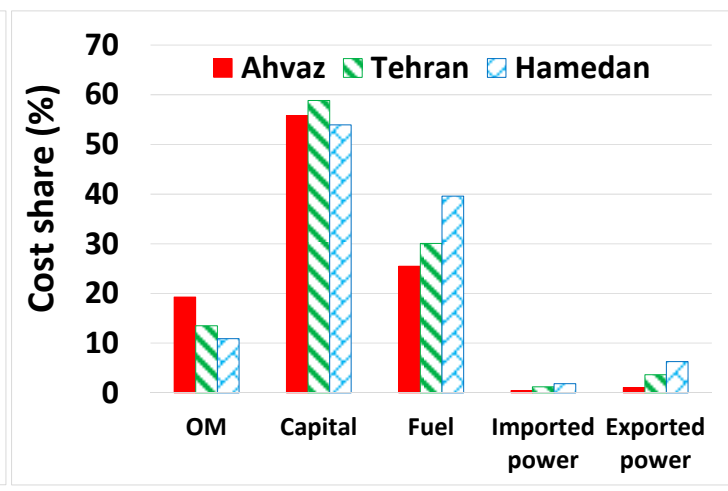

(b)

Figure 12. Total cost (a) and cost/income breakdown (b) for the polygeneration system in each city.

The share of the capital cost in Ahvaz, Tehran, and Hamedan are around 56\%, 59\% and 54\%, respectively, and the differences between these values are not significant. However, the share of fuel cost is the highest in Hamedan (40\%) and the lowest in Ahvaz (26\%). Despite the highest share of PV power generation in Hamedan, the share of fuel cost in a cold city, such as Hamedan, is significantly larger than a hot city like Ahvaz, which is mainly due to the higher heating demand in Hamedan.

The payback period (PBP), ATCSR, and levelized cost of electricity (LCOE) are the metrics used in this study. To calculate the LCOE, the electricity is assumed as the main product and the produced cooling by the thermal chiller and the produced heat by the CHP as by-products, which can bring income to the system. To assign a price for the produced heat by the CHP, the production cost of the same amount of heat by a boiler is substituted. For cooling that is produced by the thermal chiller, the cost is calculated based on the electricity consumption of an electric chiller as if the cooling was produced by an electric chiller. The LCOE is a metric that is frequently used in the feasibility evaluation of power systems. However, because of the simultaneous production of electricity and useful heat in a polygeneration system, this value can be misleading and therefore it should be used along with the other metrics. As presented in Table 8, the levelized cost of electricity is the highest in Hamedan and the lowest in Ahvaz. The payback periods are relatively long for all of the cities and the implementation of the polygeneration system in Iran is not economically feasible with the current energy market. LCOE of the polygeneration system in all of the cases is higher than the price of electricity in the energy market in Iran (0.06 USD/kWh $\mathrm{el}_{\mathrm{e}}$ ). This, along with the high payback period (more than 19 years), shows that the polygeneration system is not an economically viable choice in Iran.

Table 8. Economy of the polygeneration system.

\begin{tabular}{ccc}
\hline City & LCOE (USD/kWh $\mathbf{e l})$ & Payback Period (Years) \\
\hline Ahvaz & 0.07 & 19 \\
Tehran & 0.10 & $>20$ \\
Hamedan & 0.11 & $>20$ \\
\hline
\end{tabular}

The results show that the performance of the polygeneration system in the identified case study is higher in the building that is located in a hot city, such as Ahvaz, when compared to the building located in a cold city such as Hamedan. A higher share of power production by PV units has a positive impact on the environmental performance of a polygeneration system. Using the exhaust gas of the CHP system for cooling purposes has a significant effect on the performance of the system. Moreover, the results show the significant role of the thermal chiller and cold storage in improving the performance of the polygeneration system. 
These results can be used as guidance in the planning stage of polygeneration system implementation. However, due to the large number of variables that are involved, these results cannot be generalized to other cases and every project should be investigated individually.

\section{Conclusions}

In this study, the performance of polygeneration systems for an identical building that is located in three cities in Iran with cold, moderate and hot climates has been investigated. In all of the cities, the application of the polygeneration systems shows significant environmental and energetic benefits relative to the reference system. One important finding is the importance of thermal chiller and cold storage in increasing the performance of the polygeneration systems. Effective exploitation of excess heat and power for cooling production increases the performance of the polygeneration system.

The comparative analysis shows that the polygeneration system in Ahvaz with a higher cooling demand is superior regarding energy, environment and economy. The $\mathrm{CO}_{2}$ emission reduction potential in a building that is located in Ahvaz is around $41 \%$, while this value in Hamedan is around $27 \%$. However, the economic indicators, such as low (even negative) ATCSR and high payback periods, are not promising, which can be a significant obstacle for promoting the application of the polygeneration systems. As a general conclusion, regardless of the energetic and environmental benefits of the polygeneration system in the case studies, with the presented electricity tariff in the residential building in Iran, the implementation of a polygeneration energy system is not economically feasible. Various financial mechanisms, such as feed-in-tariffs, tax reduction, and subsidies, can promote the application of these systems.

Author Contributions: S.G.S. conceived and designed the model; A.M. and V.M. contributed jointly by supervising the overall work and the overall structure of the paper; S.G.S. wrote the paper.

Acknowledgments: This work was financially supported by the ST and UP for Energy project, within the Swedish Government's strategic research.

Conflicts of Interest: The authors declare no conflict of interest.

\section{Nomenclature}

$\begin{array}{ll}\text { ATCSR } & \text { Annualized total cost saving ratio (\%) } \\ \mathrm{c} & \text { cooling }(\mathrm{kW}) \\ \text { CHP } & \text { Combined heat and power } \\ \text { CCHP } & \text { Combined cooling, heating and power } \\ \text { CO2ERR } & \mathrm{CO}_{2} \text { emission reduction ratio (\%) } \\ \text { CS } & \text { Cold storage } \\ F & \text { Fuel Energy (kWh) } \\ \text { FEL } & \text { Following electric load } \\ \text { FTL } & \text { Following thermal load } \\ \text { FSR } & \text { Fuel saving ratio (\%) } \\ \text { H } & \text { Heating (kWth) } \\ \text { HRU } & \text { Heat recovery unit } \\ \text { HS } & \text { Heat storage } \\ \text { i } & \text { Nominal discount rate (\%) } \\ \text { ISR } & \text { Integrated saving ratio (\%) } \\ \text { LCOE } & \text { Levelized cost of electricity } \\ \text { MBL } & \text { Modified base load } \\ \text { NPV } & \text { Net present value } \\ \text { PBP } & \text { Payback period (year) } \\ \text { PL } & \text { Part-load (\%) } \\ \text { PSO } & \text { Particle swarm optimization } \\ \text { w } & \text { Weight factor }\end{array}$




\begin{tabular}{ll} 
Subscripts & \\
bat & Battery storage \\
cs & Cold storage \\
Dem & Demand \\
dl & Distribution line \\
Ech & Electric chiller \\
el & Electricity \\
exp & Export \\
hru & Heat recovery unit \\
hs & Heat storage \\
imp & Import \\
in & Input \\
out & Output \\
shu & Solar heater unit \\
sup & Supply \\
Tch & Thermal chiller \\
th & Thermal \\
tot & Total \\
wind & Wind turbine \\
Grid & Utility grid \\
Poly & Polygeneration system \\
Ref & Reference system \\
Greek Letters & \\
$\eta$ & Efficiency (\%) \\
& \\
\hline &
\end{tabular}

\section{References}

1. U.S. Energy Information Administration (EIA). International Energy Outlook 2016; U.S. Energy Information Administration: Washington, DC, USA, 2016.

2. Dean, B.; Dulac, J.; Petrichenko, K.; Graham, P. Towards Zero-Emission Efficient and Resilient Buildings Global Status Report 2016; United Nations Environment Programme (UNEP): Nairobi, Kenya, 2016.

3. Piacentino, A.; Barbaro, C. A comprehensive tool for efficient design and operation of polygeneration-based energy $\mu$ grids serving a cluster of buildings. Part II: Analysis of the applicative potential. Appl. Energy 2013, 111, 1222-1238. [CrossRef]

4. Mancarella, P. MES (multi-energy systems): An overview of concepts and evaluation models. Energy 2014, 65, 1-17. [CrossRef]

5. Calise, F.; Dentice D'Accadia, M. Simulation of polygeneration systems. Energies 2016, 9, 925. [CrossRef]

6. Moya, M.; Bruno, J.C.; Eguia, P.; Torres, E.; Zamora, I.; Coronas, A. Performance analysis of a trigeneration system based on a micro gas turbine and an air-cooled, indirect fired, ammonia-water absorption chiller. Appl. Energy 2011, 88, 4424-4440. [CrossRef]

7. Calise, F.; Figaj, R.D.; Vanoli, L. A novel polygeneration system integrating photovoltaic/thermal collectors, solar assisted heat pump, adsorption chiller and electrical energy storage: Dynamic and energy-economic analysis. Energy Convers. Manag. 2017, 149, 798-814. [CrossRef]

8. Calise, F.; Dentice d'Accadia, M.; Piacentino, A.; Vicidomini, M. Thermoeconomic optimization of a renewable polygeneration system serving a small isolated community. Energies 2015, 8, 995-1024. [CrossRef]

9. El-Khattam, W.; Salama, M.M.A. Distributed generation technologies, definitions and benefits. Electr. Power Syst. Res. 2004, 71, 119-128. [CrossRef]

10. Al Moussawi, H.; Fardoun, F.; Louahlia-Gualous, H. Review of tri-generation technologies: Design evaluation, optimization, decision-making, and selection approach. Energy Convers. Manag. 2016, 120, 157-196. [CrossRef]

11. Jana, K.; Ray, A.; Majoumerd, M.M.; Assadi, M.; De, S. Polygeneration as a future sustainable energy solution-A comprehensive review. Appl. Energy 2017, 202, 88-111. [CrossRef]

12. Jradi, M.; Riffat, S. Tri-generation systems: Energy policies, prime movers, cooling technologies, configurations and operation strategies. Renew. Sustain. Energy Rev. 2014, 32, 396-415. [CrossRef] 
13. Ghaem Sigarchian, S.; Malmquist, A.; Martin, V. Optimal planning and design method for complex polygeneration systems: A case study for a residential building in Italy. Energy Convers. Manag. 2018, under review.

14. Romero Rodríguez, L.; Salmerón Lissén, J.M.; Sánchez Ramos, J.; Rodríguez Jara, E.Á.; Álvarez Domínguez, S. Analysis of the economic feasibility and reduction of a building's energy consumption and emissions when integrating hybrid solar thermal/PV/micro-CHP systems. Appl. Energy 2016, 165, 828-838. [CrossRef]

15. Di Somma, M.; Yan, B.; Bianco, N.; Graditi, G.; Luh, P.B.; Mongibello, L.; Naso, V. Multi-objective design optimization of distributed energy systems through cost and exergy assessments. Appl. Energy 2017, 204, 1299-1316. [CrossRef]

16. Sanaye, S.; Hajabdollahi, H. Thermo-Economic Optimization of Solar CCHP Using Both Genetic and Particle Swarm Algorithms. J. Sol. Energy Eng. 2014, 137, 11001. [CrossRef]

17. Tichi, S.G.; Ardehali, M.M.; Nazari, M.E. Examination of energy price policies in Iran for optimal configuration of CHP and CCHP systems based on particle swarm optimization algorithm. Energy Policy 2010, 38, 6240-6250. [CrossRef]

18. Hanafizadeh, P.; Eshraghi, J.; Ahmadi, P.; Sattari, A. Evaluation and sizing of a CCHP system for a commercial and office buildings. J. Build. Eng. 2016, 5, 67-78. [CrossRef]

19. Ghaem Sigarchian, S.; Malmquist, A.; Martin, V. The choice of operating strategy for a complex polygeneration system: A case study for a residential building in Italy. Energy Convers. Manag. 2018, 163, 278-291. [CrossRef]

20. Kennedy, J.; Eberhart, R. Particle Sawrm Optimization. In Proceedings of the IEEE International Conference of Neural Networks, Perth, Western Australia, 27 November-1 December 1995; pp. 1943-1948.

21. Hu, X. Particle Swarm Optimization. Available online: http://www.swarmintelligence.org (accessed on 15 May 2015).

22. Basrawi, F.; Yamada, T.; Nakanishi, K.; Naing, S. Effect of ambient temperature on the performance of micro gas turbine with cogeneration system in cold region. Appl. Therm. Eng. 2011, 31, 1058-1067. [CrossRef]

23. Hajabdollahi, H.; Ganjehkaviri, A.; Jaafar, M.N.M. Assessment of new operational strategy in optimization of CCHP plant for different climates using evolutionary algorithms. Appl. Therm. Eng. 2015, 75, 468-480. [CrossRef]

24. Li, M.; Jiang, X.Z.; Zheng, D.; Zeng, G.; Shi, L. Thermodynamic boundaries of energy saving in conventional CCHP (Combined Cooling, Heating and Power) systems. Energy 2016, 94, 243-249. [CrossRef]

25. Ebrahimi, M.; Keshavarz, A. Climate impact on the prime mover size and design of a CCHP system for the residential building. Energy Build. 2012, 54, 283-289. [CrossRef]

26. Ebrahimi, M.; Keshavarz, A. Sizing the prime mover of a residential micro-combined cooling heating and power (CCHP) system by multi-criteria sizing method for different climates. Energy 2013, 54, 291-301. [CrossRef]

27. Cho, H.; Mago, P.J.; Luck, R.; Chamra, L.M. Evaluation of CCHP systems performance based on operational cost, primary energy consumption, and carbon dioxide emission by utilizing an optimal operation scheme. Appl. Energy 2009, 86, 2540-2549. [CrossRef]

28. IEA EBC Annex 54. Methodologies for the Performance Assessment of Micro Hybrid Polygeneration Systems; IEA EBC Annex 54 Integration of Micro-Generation and Related Energy Technologies in Buildings, Technische Universität München: München, Germany, 2014; Volume 10.

29. Barbieri, E.S.; Spina, P.R.; Venturini, M. Analysis of innovative micro-CHP systems to meet household energy demands. Appl. Energy 2012, 97, 723-733. [CrossRef]

30. Ehyaei, M.A.; Mozafari, A. Energy, economic and environmental (3E) analysis of a micro gas turbine employed for on-site combined heat and power production. Energy Build. 2010, 42, 259-264. [CrossRef]

31. Bianchi, M.; De Pascale, A.; Spina, P.R. Guidelines for residential micro-CHP systems design. Appl. Energy 2012, 97, 673-685. [CrossRef]

32. Wang, J.; Zhai, Z.J.; Jing, Y.; Zhang, C. Particle swarm optimization for redundant building cooling heating and power system. Appl. Energy 2010, 87, 3668-3679. [CrossRef]

33. Wang, J.-J.; Zhang, C.-F.; Jing, Y.-Y. Multi-criteria analysis of combined cooling, heating and power systems in different climate zones in China. Appl. Energy 2010, 87, 1247-1259. [CrossRef]

34. Ghaem Sigarchian, S.; Orosz, M.S.; Hemond, H.F.; Malmquist, A. Optimum design of a hybrid PV-CSP-LPG microgrid with Particle Swarm Optimization technique. Appl. Therm. Eng. 2016, 109, 1031-1036. [CrossRef] 
35. Tudu, B.; Majumder, S.; Mandal, K.K.; Chakraborty, N. Comparative performance study of genetic algorithm and particle swarm optimization applied on off-grid renewable hybrid energy system. In SEMCCO 2011: Swarm, Evolutionary, and Memetic Computing, Lecture Notes in Computer Science; Springer: Berlin/Heidelberg, Germany, 2011; Volume 7076.

36. Ehyaei, M.A.; Bahadori, M.N. Selection of micro turbines to meet electrical and thermal energy needs of residential buildings in Iran. Energy Build. 2007, 39, 1227-1234. [CrossRef]

37. Kasmaei, M. Building and Housing Research Center Affiliated to the Ministry of Housing and Urban Development; Building and Housing Research Center: Tehran, Iran, 1992.

38. TRNSYS TRNSYS 17, Transient System Simulation Program. Available online: http://sel.me.wisc.edu/ trnsys / (accessed on 15 January 2017).

39. Azadi, P.; Mahmoudzadeh, A.; Shirvani, T. The Outlook for Natural Gas, Electricity, and Renewable Energy in Iran; Working Paper 3, Stanford Iran 2040 Project; Stanford University: Stanford, CA, USA, 2017.

40. Iran Ministry of Energy (MOE). Electric Power Industry in Iran 2015-2016; Tavanir Expert Holding Company: Tehran, Iran, 2015.

41. Polaris America, LLC. Available online: http://www.polarisamerica.com/turbines/20kw-wind-turbines / (accessed on 15 January 2017).

42. Capstone Technical Support Technical Reference Capstone C30 Microturbine 2006; Capstone Turbine Corporation: Chatsworth, CA, USA, 2006. Available online: https:/ /www.capstoneturbine.com (accessed on 15 February 2016).

43. Capstone Turbine Corporation Capstone Turbine Corporation Capstone C1000 Series Microturbine Systems 2011; Capstone Turbine Corporation: Chatsworth, CA, USA, 2011. Available online: https: / www.capstoneturbine. com (accessed on 15 February 2016).

44. Capstone Technical Support Technical Reference Capstone C200 Microturbine; Capstone Turbine Corporation: Chatsworth, CA, USA, 2009. Available online: https:/ / www.capstoneturbine.com (accessed on 15 February 2016).

45. Tang, T.; Villarreal, L. Guideline: Absorption Chillers; New Buildings Institute: Fair Oaks, CA, USA, 1998.

46. International Energy Agency (IEA); Beerepoot, M. Technology Roadmap: Solar Heating and Cooling; OECD/IEA International Energy Agency IEA Publishing: Paris, France, 2012.

47. Capehart, B.L. Microturbines. Available online: https://www.wbdg.org/resources/microturbines.php (accessed on 15 May 2017).

48. Selection, M.; Manual, D. BROAD X Absorption Chiller Model Selection \& Design Manual; Broad Air Conditioning: Changsha Broad Town, China, 2008.

49. ICF International Inc; Hampson, A.; Deaver, P.; Neff, B.; Bender, S.; Oglesby, R. Combined Heat and Power: Policy Analysis and 2011-2030; California Energy Commission: Sacramento, CA, USA, 2012.

50. Itron Inc. 2010-2012 WO017 ex Ante Measure Cost Study Final Report; California Public Utilities Commission: Oakland, CA, USA, 2014.

51. IEA-ETSAP and IRENA Technology Brief E17. Thermal Energy Storage Technology Brief. IEA-ETSAP \& IRENA, 2013. Available online: http://www.irena.org/publications/2013/Jan/IRENA-IEA-ETSAPTechnology-Briefs (accessed on 15 March 2015).

52. Roth, K.; Zogg, R.; Brodreick, J. Cool thermal energy storage. ASHRAE J. 2006, 48, 94-96.

53. Moshiri, S. Energy Price Reform and Energy Efficiency in Iran. IAEE Energy Forum 2013, 33-37. Available online: https: / / ssrn.com/abstract=2335755 (accessed on 15 January 2017).

54. European Union. How to Develop a Sustainable Energy Action Plan (SEAP)—Guidebook; European Commission, Covenant of Mayors, Publications Office of the European Union: Luxembourg, 2010.

55. Brander, M.; Sood, A.; Wylie, C.; Haughton, A.; Lovell, J.; Reviewers, I.; Davis, G. Electricity-specific emission factors for grid electricity. Ecometrica 2011. Available online: https://ecometrica.com/whitepapers/electricity-specific-emission-factors-for-grid-electricity (accessed on 15 February 2015).

(C) 2018 by the authors. Licensee MDPI, Basel, Switzerland. This article is an open access article distributed under the terms and conditions of the Creative Commons Attribution (CC BY) license (http://creativecommons.org/licenses/by/4.0/). 